\title{
CARDAIC SURGERY; RISK FACTORS OF DELAYED EXTUBATION
}

1. PGR General Surgery Nishtar Hospital Multan.

2. MBBS Student

Nishtar Medical University Multan.

3. MBBS

Medical Officer

BHU Shamkot Khanewal.

4. PGR Anesthesia

Nishtar Hospital Multan.

5. MBBS

Medical Officer

BHU Pontta Tehsil Shujabad,

Multan.

Correspondence Address:

Dr. Junaid Zia Hashmi

(PGR General Surgery),

Address: House No. IX1775/261,

Almisbah, 1 Tariqabad Colony,

Near Civil Lines College,

Multan Pakistan.

juneehashmi@yahoo.com

Article received on:

$13 / 07 / 2017$

Accepted for publication:

$15 / 10 / 2017$

Received after proof reading:

$29 / 11 / 2017$

\section{Junaid Zia Hashmi', Kanza Zia Hashmi², Faisal Zaheer ${ }^{3}$, Zaigham Hussain ${ }^{4}$, Kashif Mustafa}

ABSTRACT... Objectives: To identify the risk factors of delayed extubation after cardiac surgery. Study Design: Observational study. Setting: Cardiac surgery in CPE Institute of Cardiology. Period: 2 months from November-2016 to March-2017. Methods: Eighty-one (81) patients who underwent cardiac surgery. In ICU we recorded extubation time of all patients. Patients with extubation time $\leq 6$ hours after labelled as early extubation group and those with extubation time $>6$ hours were labelled as delayed extubation group. We recorded their preoperative risk factors and operative variables of surgery to identify the risk factors that leads to late extubation after cardiac surgery (CS). Results: Prevalence of diabetes was significantly high in patients with delayed extubation. There were $42.3 \%$ diabetic patients with delayed extubation and only $12.7 \%$ diabetic patients with early extubation ( $p$-value 0.003 ). Total pump time, cross clamp time and type of operation were similar between the groups. Cardiovascular instability was the most common cause of delayed extubation that occurred in 9 patients, reduced level of consciousness in 9 patients, post-op bleeding in 6 patients, while hypoxemia and increased respiratory rate occurred in 1,1 patient respectively. Conclusion: Diabetes Mellitus is an independent risk factor of delayed extubation after cardiac surgery. Cardiovascular instability, reduced level of consciousness and post-operative bleeding after surgery are the main factors that leads to delayed extubation after CS.

Key words: Cardiac Surgery, Delayed Extubation, Early Extubation.

Article Citation: Hashmi JZ, Hashmi KZ, Zaheer F, Hussain Z, Mustafa K. Cardaic surgery Risk factors of delayed extubation. Professional Med J 2017;24(12):18401843. DOI:10.17957/TPMJ/17.4157

\section{INTRODUCTION}

Many advancements have been made regarding anesthetic and sedation regimens to reduce the duration of intubation after cardiac surgery. ${ }^{1}$ Because delayed extubation is associated with considerable increase in health care resources and worsening of patient's outcomes after cardiac surgery. ${ }^{2-5}$ Weaning off the patient from mechanical ventilation within 6-8 hours after surgery is defined as early extubation. In patients with prolonged extubation period, ICU stay period is increased resulting in increase in cost of the procedure. Delayed extubation is most commonly done due to the fear of myocardial ischemia and high doses of narcotics during anesthesia. ${ }^{6}$

Trend of early extubation after cardiac have gained much importance in the present era because of the theoretical benefits of early extubation and considerable reduction in healthcare cost of patients. ${ }^{7}$ however, some researches did not found significant differences in hospital stay of patients with early and delayed extubation and some have found significant benefits of early extubation over prolonged extubation. ${ }^{8,9}$ Despite many efforts of early extubation, many patients after cardiac surgery failed to extubate early due to several risk factors. ${ }^{10}$ Recognition of these risk factors of delayed extubation after cardiac surgery may help us to manage ICU resources in a better way. In present study we tried to identify the risk factors of delayed extubation after cardiac surgery.

\section{METHODS}

This observational study included eighty-one (81) patients who underwent cardiac surgery in CPE institute of cardiology. The duration of study was 2 months from November-2016 to March-2017. In ICU we recorded extubation time of all patients. 
Patients with extubation time $\leq 6$ hours after labelled as early extubation group and those with extubation time $>6$ hours were labelled as delayed extubation group. We recorded their risk factors of heart disease and operative variables of surgery. Informed consent from relatives of patients was taken before selecting patient's data for study. Ethical approval from academic affair department of the hospital was also taken. All patients undergoing cardiac surgery such as coronary heart surgery and valvular operations, and congenital cardiac procedures were included. Patients who underwent off pump procedures and neonates and infant patients were excluded. We also recorded the main post-procedural risk factors of delayed extubation.

Descriptive statistics were used to present patient variables. Analysis was done using SPSS v16. Female gender, risk factors and type of procedure were compared using Chi-square test. Patients age, pump time and cross-clamp time were compared using student's t-test. P-value $\leq 0.05$ was considered significant.

\section{RESULTS:}

In Table-I Comparison of cardiovascular risk factors and operative variables is given. Prevalence of diabetes was significantly high in patients with delayed extubation. There were 42.3\% diabetic patients with delayed extubation and only $12.7 \%$ diabetic patients with early extubation ( $p$-value 0.003). Total pump time, cross clamp time and type of operation were similar between the groups.

Cardiovascular instability was the most common cause of delayed extubation that occurred in 9 patients, reduced level of consciousness in 9 patients, post-op bleeding in 6 patients, while hypoxemia and increased respiratory rate occurred in 1, 1 patient respectively (Figure-1).

\begin{tabular}{|l|c|c|c|}
\hline & $\begin{array}{c}\text { Early Extubation } \\
(\mathbf{N = 5 5 )}\end{array}$ & $\begin{array}{c}\text { Delayed Extubation } \\
(\mathbf{N = 2 6 )}\end{array}$ & P-value \\
\hline Age (Y) & $41.36 \pm 18.00$ & $42.76 \pm 15.52$ & 0.73 \\
\hline Female Gender (\%) & $14(25.5)$ & $6(23.1)$ & 0.81 \\
\hline Smoking (\%) & $13(23.6)$ & $8(30.8)$ & 0.49 \\
\hline Diabetes (\%) & $7(12.7)$ & $11(42.3)$ & 0.003 \\
\hline Hypertension (\%) & $16(29.1)$ & $10(38.5)$ & 0.39 \\
\hline Emergency Operation (\%) & $0(0.0)$ & $1(3.8)$ & 0.14 \\
\hline Pump time (mins) & $113.53 \pm 42.45$ & $119.04 \pm 48.11$ & 0.62 \\
\hline Cross-clamp time (mins) & $73.88 \pm 30.75$ & $75.76 \pm 39.79$ & 0.82 \\
\hline Use of Inotropes >12 hours & $10(18.2)$ & $6(23.1)$ & 0.60 \\
\hline Type of Operation & & & \\
\hline CABG (\%) & $32(58.2)$ & $16(61.5)$ & 0.27 \\
\hline Valvular operation (\%) & $18(32.7)$ & $5(19.2)$ & \\
\hline Congenital (\%) & $4(15.4)$ & $4(15.4)$ & \\
\hline Aneurysm (\%) & $1(3.8)$ & $1(1.2)$ & \\
\hline
\end{tabular}

Table-I. Comparison of cardiovascular risk factors and operative variables.

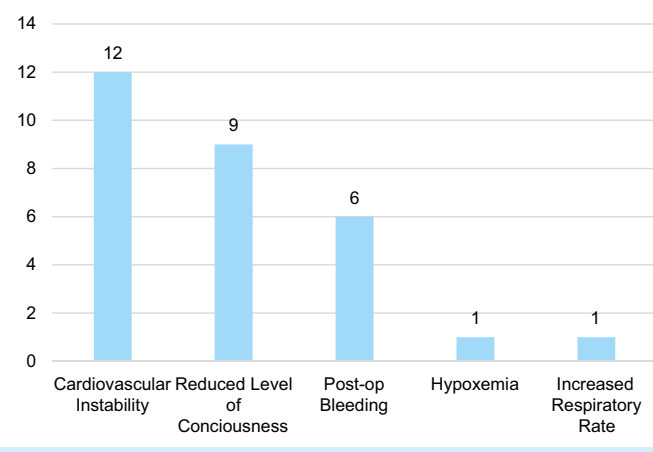

Figure-1. Causes of delayed extubation.

\section{DISCUSSION}

In this study, we evaluated the pre-operative and operative risk factors of delayed extubation. We found only diabetes as an independent risk factor of delayed extubation in our patients. While there was no significant effect of age, gender, hypertension and smoking on delayed extubation. In our study, there was no effect of bypass time, cross clamp time and type of operation on delayed extubation in cardiac surgery patients. 
Some studies, on the other hand have found older age as a risk factor of delayed extubation and these studies have found age $>65$ year is a risk factor of delayed extubation after surgery. ${ }^{11,12}$ According to Suematsu et al. risk of delayed extubation is increased in patients with age $>70$ Years. $^{3}$

In our study, there was no effect of female gender on delayed extubation. In study by Shanbazi et al. female gender was more prevalent in delayed extubation group. Some other studies have also found higher prevalence of female gender in patients with delayed extubation. Rezaianzadeh et al. did not found effect of female gender on delayed extubation. ${ }^{13}$ Suematsu et al. ${ }^{3}$ also did not found female gender as a risk factor of delayed extubation.

Christian et al. ${ }^{14}$ reported hypertension, diabetes, Female sex, COPD and higher BMI as risk factors of delayed extubation after cardiac surgery. Rezaianzadeh et al. $^{13}$ reported that need of packed cells and inotropes during and after cardiopulmonary bypass and low arterial pressures after surgery are risk factors of delayed extubation after cardiac surgery.

In our study, there was no effect of total pump time on delayed extubation. Shahbaziet el. ${ }^{15}$ also did not found any effect of pump time on delayed extubation. Imanipour et al. ${ }^{16}$ also did not found any effect of pump time on delayed extubation in patients after cardiac surgery. Cislaghi et al. ${ }^{17}$ on the contrary found significant effect of pump time on duration of extubation and found that pump time more than 91 minutes is an independent risk factor of delayed extubation after cardiac surgery. These authors also found that infusion of $>4$ blood units or administration of fresh frozen plasma is also associated with prolonged mechanical ventilation. Several other studies have also found similar effects of blood transfusions and inotropic support on mechanical ventilation duration. ${ }^{18-20}$ Kogan et al. ${ }^{21}$ found that kidney failure, stroke, peri-op bleeding and infection as main contributing factors of delayed extubation after surgery. Higgins et also found kidney failure as a risk factor of delayed extubation. ${ }^{22}$
Dunning et al. ${ }^{23}$ found that left ventricular systolic dysfunction and urgency of the procedure as independent risk factors of prolonged ventilation after surgery. Prapas et al. ${ }^{11}$ concluded that periop need IABP insertion is also an independent risk factor of delayed extubation after CABG surgery. According to Shirzadet al. ${ }^{24}$ atrial fibrillation, sudden cardiac arrest and need for intubation are common risk factors of delayed extubation after valvular heart surgery.

So different researchers have found different risk factors of delayed extubation after cardiac surgery. In our study, we only found female gender as a pre-operative risk factor of prolonged mechanical ventilation after cardiac surgery. In our study, cardiovascular instability, reduced level of consciousness and post-operative bleeding were the main reasons of delayed extubation.

Copyright (C) 15 Oct, 2017.

\section{REFERENCES}

1. Cheng DC. Fast Track Cardiac Surgery Pathways Early Extubation, Process of Care, and Cost Containment. J Am Soc Anesthes. 1998;88(6):1429-33.

2. Cislaghi F, Condemi AM, Corona A. Predictors of prolonged mechanical ventilation in a cohort of 5123 cardiac surgical patients. Eur J Anaesthesiol. 2009;26(5):396-403.

3. Suematsu Y, Sato H, Ohtsuka T, Kotsuka Y, Araki S, Takamoto S. Predictive risk factors for delayed extubation in patients undergoing coronary artery bypass grafting. HeartVessels. 2000;15(5):214-20.

4. Meade MO, Guyatt G, Butler R, Elms B, Hand L, Ingram $A$, et al. Trials comparing early vs late extubation following cardiovascular surgery. CHEST J. 2001;120(6_suppl):445S-53S.

5. Reyes A, Vega G, Blancas R, Morato B, Moreno J-L, Torrecilla $C$, et al. Early vs conventional extubation after cardiac surgery with cardiopulmonary bypass. Chest. 1997;112(1):193-201.

6. Amirghofran A, Rayatpisheh M, Rayatpisheh S, Kaviani M. A comparative study of immediate and late extubation after open heart surgery. Int Cardivasc Res J Safnek. 2007;1:42-9.

7. Moran J, Peisach A, Solomon P, Martin J. Cost calculation and prediction in adult intensive care: a ground-up utilization study. Anesth Intensive Care. 2004;32(6):787-97. 
8. Walthall $H$, Ray $S$. Do intraoperative variables have an effect on the timing of tracheal extubation after coronary artery bypass graft surgery? Heart Lung. 2002;31(6):432-9.

9. Prakash O, Jonson B, Meij S, Bos E, Hugenholtz PG, Nauta J, et al. Criteria for early extubation after intracardiac surgery in adults. Anesth Analg. 1977;56(5):703-8.

10. Yende S, Wunderink R. Causes of prolonged mechanical ventilation after coronary artery bypass surgery. CHEST J. 2002;122(1):245-52.

11. Prapas SN, Panagiotopoulos IA, Abdelsalam AH, Kotsis VN, Protogeros DA, Linardakis IN, et al. Predictors of prolonged mechanical ventilation following aorta notouch off-pump coronary artery bypass surgery. Eur J Cardio-thorac Surg. 2007;32(3):488-92.

12. Filsoufi F, Rahmanian PB, Castillo JG, Chikwe J, Adams $\mathrm{DH}$. Logistic risk model predicting postoperative respiratory failure in patients undergoing valve surgery. Eur J Cardio-Thorac Surg. 2008;34(5):953-9.

13. Rezaianzadeh A, Maghsoudi B, Tabatabaee H, Keshavarzi S, Bagheri Z, Sajedianfard J, et al. Factors associated with extubation time in coronary artery bypass grafting patients. PeerJ. 2015;3:e1414.

14. Christian K, Engel AM, Smith JM. Predictors and outcomes of prolonged ventilation after coronary artery bypass graft surgery. Am Surg. 2011;77(7):9427.

15. Shahbazi S, Kazerooni M. Predictive factors for delayed extubation in the intensive care unit after coronary artery bypass grafting; a Southern Iranian experience. IranJMed Sci. 2012;37(4):238-41.

16. Imanipour M, Bassampoor SS, NikbakhtNA. Intraoperative variables associated with extubation time in patients undergoing coronary artery bypass graft surgery. Jpn J Nurs Sci. 2008;5(1):23-30.
17. Cislaghi F, Condemi A, Corona A. Predictors of prolonged mechanical ventilation in a cohort of 3,269 CABG patients. Minerva Anestesiol. 2007;73(12):61521.

18. Faritous ZS, Aghdaie N, Yazdanian F, Azarfarin R, Dabbagh A. Perioperative risk factors for prolonged mechanical ventilation and tracheostomy in women undergoing coronary artery bypass graft with cardiopulmonary bypass. Saudi JAnaesth. 2011;5(2):167-9.

19. Scott BH, Seifert FC, Grimson R. Blood transfusion is associated with increased resource utilisation, morbidity and mortality in cardiac surgery. AnnCardAnaesth. 2008;11(1):15-9.

20. Totonchi Z, Baazm F, Chitsazan M, Seifi S, Chitsazan $M$. Predictors of prolonged mechanical ventilation after open heart surgery. J Cardiovasc Thorac Res. 2014;6(4):211-6.

21. Kogan A, Ghosh P, Preisman S, Tager S, Sternik L, Lavee J, et al. Risk factors for failed "fast-tracking" after cardiac surgery in patients older than $\mathbf{7 0}$ years. JCardiothorac Vasc Anesth. 2008;22(4):530-5.

22. Higgins TL, Estafanous FG, Loop FD, Beck GJ, Blum JM, Paranandi L. Stratification of morbidity and mortality outcome by preoperative risk factors in coronary artery bypass patients. J Am Med Assoc.1992; 267:2344-48.

23. Dunning $\mathrm{J}, \mathrm{Au} \mathrm{J}$, Kalkat $\mathrm{M}$, Levine A. A validated rule for predicting patients who require prolonged ventilation post cardiac surgery. Eur $\mathrm{J}$ Cardio-Thorac Surg. 2003;24(2):270-6.

24. Shirzad M, Karimi A, Ahmadi SH, Marzban M, Tazik M, Aramin $\mathrm{H}$. Predictors and early outcome of prolonged mechanical ventilation in contemporary heart valve surgery. Monaldi Arch Chest Dis. 2015;74(1):22-7.

\begin{tabular}{|c|c|c|c|}
\hline \multicolumn{4}{|c|}{ AUTHORSHIP AND CONTRIBUTION DECLARATION } \\
\hline Sr. \# & Author-s Full Name & Contribution to the paper & Author $=\mathbf{s}$ Signature \\
\hline 2 & $\begin{array}{l}\text { Junaid Zia Hashmi } \\
\text { Kanza Zia Hashmi }\end{array}$ & $\begin{array}{l}\text { Abstract, Introduction and } \\
\text { Discussion, Data compilation. } \\
\text { Results, Data analysis and } \\
\text { compilation. }\end{array}$ & \\
\hline 3 & Faisal Zaheer & Discussion and Data compilation & \\
\hline 4 & Zaigham Hussain & Data compilation and analysis & \\
\hline 5 & Kashif Mustafa & Data compilation and analysis & \\
\hline
\end{tabular}

